\title{
Systemic Lupus Erythematosus: Recent Concepts in Genomics, Pathogenetic Mechanisms, and Therapies
}

\author{
Sriram Krishnamurthy and Subramanian Mahadevan \\ Department of Pediatrics, Jawaharlal Institute of Postgraduate Medical Education and Research (JIPMER), \\ Pondicherry 605006, India \\ Correspondence should be addressed to Subramanian Mahadevan, smaha1232@rediffmail.com
}

Received 20 July 2011; Accepted 17 August 2011

Academic Editors: A. Bondanza, A. Rebollo, and B. Stijlemans

Copyright (C 2011 S. Krishnamurthy and S. Mahadevan. This is an open access article distributed under the Creative Commons Attribution License, which permits unrestricted use, distribution, and reproduction in any medium, provided the original work is properly cited.

\begin{abstract}
Systemic lupus erythematosus (SLE) is a chronic multisystem autoimmune disorder associated with multiple immunological abnormalities and a wide range of clinical manifestations. Recent progress in genetics has expanded the number of the genes associated with SLE to more than 20 in number and has contributed to improvement of understanding of the pathogenesis of the disease. This has enhanced the development of novel therapeutic targets and biomarkers for individualized and tailor-made clinical management of lupus patients. Despite this knowledge, however, it is a challenge to fully understand the genetic pathogenesis of the disease. The present paper describes the current concepts in the mechanisms, genomics, and pathogenesis of SLE and their implications for management of the disorder. The potential role of gene therapy, biological agents, intravenous immunoglobulin, anti-inflammatory cytokines, and cytokine inhibitors is discussed.
\end{abstract}

\section{Introduction}

Systemic lupus erythematosus (SLE) is a chronic multisystem autoimmune disorder characterized by the development of autoantibodies and immune complexes in association with a wide variety of clinical manifestations and tissue damage. Several defects of multiple immunological components play a role in the pathogenesis of SLE [1]. A wide range of immunological abnormalities have been described in SLE, and include the ability to produce pathogenic autoantibodies, lack of T- and B-lymphocyte regulation, and defective clearance of autoantigens and immune complexes. Majority of autoantibodies found in lupus are directed at intracellular nucleoprotein particles, with $98 \%$ of patients demonstrating antinuclear antibodies, while anti-double-stranded DNA (dsDNA) antibodies are found in $50-80 \%$ of patients [2]. These latter autoantibodies are exclusive to lupus. The precise etiology of SLE remains to be defined; however, it is known that genetic predisposition and environmental and hormonal factors play important roles. These factors interact to transform complex relations between the host, pathogens, and the environment. Along with recent advances in genetic research, newly discovered genes associated with SLE confirm the preexisting concept of pathogenesis and may also provide new biologic insights into the pathogenesis of the disorder [3]. We herein review the current concepts in the mechanisms, genomics, and pathogenesis of SLE and their potential implications for management of the disorder.

\section{Pathogenic Mechanisms}

SLE is characterized by exacerbations and remissions with various clinical manifestations affecting multiple organ systems, including the skin, kidney, joints, cardiovascular, and nervous system. Three important factors have been identified in the pathogenesis of SLE: endocrine-metabolic, environmental, and genetic [2].

The predominance of lupus in females suggests that hormones play a significant role in susceptibility. Environmental factors that cause or exacerbate SLE include viruses (e.g., Epstein Barr virus) and chemicals. However no firm conclusion has been made in this regard, although cross-reactivity between antibodies to autoantigens such as Ro and Sm found 
in lupus patients and antibodies to viruses has been observed [4]. Ultraviolet light, sunlight as well as the syndrome of drug-induced lupus by hydralazine, procainamide, and isoniazid are well recognized as important etiological factors. The potential risks of oral contraceptives in young females with SLE have been mentioned [1]. The general consensus is that environmental agents cause disease only in individuals with a genetic predisposition. In studies from twins, the concordance rate for SLE was found to be $24 \%$ in monozygotic twins, but only $3 \%$ in dizygotic twins [5]. Major histocompatibility complex (MHC) as well as non-MHC loci have been identified as important etiological factors. The incidence of SLE is three to eight times higher in Asian and Black populations than in the western hemisphere. A host of immunological abnormalities have been associated with SLE.

2.1. Immunological Abnormalities in SLE. Almost every compartment of the immune system has been reported to be abnormal in lupus. It is unclear which of the many immunological defects has a causal relation with lupus and which are effects of the disease process.

2.2. T Lymphocyte and Natural Killer (NK) Cell. There is evidence for reduced numbers of CD8 $\mathrm{T}$ cells, functional defects, and sustained activation. It has been suggested that a major factor responsible for sustained activation of lymphocytes and breakdown of self-tolerance is the persistence of antigens because of poor clearance and increased apoptosis. In human patients with lupus, decreased numbers of $\mathrm{T}, \mathrm{B}$, and NK cells are common [2]. In addition to decrease in the number of cells, there are known functional abnormalities [7, 8]. CD8 T cells and NK cells have decreased cytotoxic activity. Moreover, the property of these two cell subpopulations to reduce autoantibody production by B-lymphocytes is decreased in lupus. On the contrary, these two cell populations increase IgG production in lupus patients. This abnormality has been attributed partly to defective production of transforming growth factors beta (TGF- $\beta$ ).

Abnormalities in cytokine production by $\mathrm{T}$ lymphocytes have also been demonstrated. One of the most consistent observations regarding cytokine production in lupus, which is widely targeted for gene therapy, is the general inability to make TGF- $\beta$ [9]. Reduction in this cytokine might account for sustained T- and B-lymphocyte hyperactivity possibly owing reduced regulatory T-lymphocytes that require TGF- $\beta$ to mediate their effects $[2,10,11]$.

It is therefore possible to predict that restoration of normal T-lymphocyte functions might correlate with disease remission. For example, remission with reconstitution of Tcell function has been seen in patients who were treated with cyclophosphamide. In these patients, clinical improvement, disappearance of anti-DNA antibodies, normalization of complement, and disappearance of the sequelae of chronic inflammation were followed by normalization of T-lymphocyte proliferation [12]. Resetting the immune system in lupus patients with high doses of cyclophosphamide followed by autologous stem cell transplantation has resulted in clinical remission and normalization of T-lymphocyte functions [12].

2.3. B Lymphocytes. The hallmark of systemic lupus erythematosus is the production of an array of IgG and IgM autoantibodies directed against one or more nuclear components, the most frequent of which are double stranded (ds) DNA and/or single stranded (ss) DNA. Both anti-ssDNA and anti-dsDNA are involved in disease development [13]. Clinicians consider anti-dsDNA autoantibodies to be fairly disease specific, while anti-ssDNA to be nonspecific. Anti-dsDNA autoantibodies bind to nucleosomes, laminin, collagen type IV, and heparan sulphate and may lead to nephritis. Other antibodies such as antiphospholipid [14], antineuronal, antiRo, antierythrocyte, antilymphocytes, and antiplatelet antibodies also participate directly in tissue damage [2]. Lupuslike autoimmunity can ensue due to B cell hyperactivity, with either minimal or no contribution from T-lymphocytes [2]. Table 1 summarizes the antibodies associated with various phenotypical presentations of lupus.

2.4. Cytokines. A variety of cytokine abnormalities have been demonstrated in SLE.

(a) Reduced production of IL2. Besides reduced production of IL-2, patients with SLE show decreased response to IL-2.

(b) Decreased production of TGF- $\beta$. The production of lymphocyte-derived TGF- $\beta$, in both its latent and active forms, is decreased in patients with SLE [9]. Further, decreased production of total TGF- $\beta$, but not active TGF- $\beta$, is associated with disease activity.

(c) High expression of IFN Y. Among the many cytokine abnormalities found in lupus, one of the most consistent has been high expression of IFN-Y [1517]. In human patients, IFN-Y may exacerbate or even precipitate SLE. Thus, administration of IFN- Y to a patient with RA induced SLE [18].

(d) Increased IL10 production by blood B-lymphocytes. IL10 is a potent stimulator of B-lymphocyte proliferation and differentiation. It also attenuates macrophage and antigen-presenting cell activation, cytokine production and has both inhibitory and stimulatory effects on T-lymphocytes.

(e) Increased IL4 production. IL-4 promotes B-lymphocyte proliferation and thus enhances the production of autoantibodies.

The association of SLE with other interleukins such as IL12 , IL-6, TNF- $\alpha$, and IL- 1 has been inconsistent and variable [2].

2.5. Complement. Complement deficiency is responsible for about $5 \%$ of all lupus patients, but at least $50 \%$ of patients with homozygous deficiencies of the early classical complement pathway develop a lupus-like disease [2]. The increased susceptibility to SLE, associated notably with C1q, C1r, C1s, 
TABLE 1: Antibodies associated with various phenotypical presentations of lupus (adapted from [6]).

\begin{tabular}{lc}
\hline Phenotypical presentation & Typical autoantibody profile \\
\hline Nephritis, photosensitivity, serositis & Anti-ds DNA \\
Photosensitivity & Anti-Ro/La \\
Neonatal lupus syndromes & Anti-Ro/La \\
Coagulopathy, thrombocytopenia, CNS syndromes & Lupus anticoagulant, antiphospholipid antibodies \\
Raynaud's disease, myositis, and cardiopulmonary lesions & Anti-RNP \\
Drug-induced lupus & Antihistone \\
\hline
\end{tabular}

and C2 deficiency, is thought to be due to impairment of immune complex clearance and solubilization $[11,19,20]$. CR1, which binds C3b and C4b fragments, is decreased in lupus patients, and levels correlate with disease activity.

2.6. Phagocytosis. Both human patients and murine models of lupus exhibit defective clearance of immune complexes. The defects are complex but the role of the Fc receptors and CR1 in clearing immune complexes, has been widely studied [21].

\section{Genomics}

Understanding the genomics of SLE offers the following advantages $[3,22,23]$ :

(a) to predict high-risk patients who carry one or more genetic susceptibility factors among the general population or within the families with a proband;

(b) to identify individuals with high-risk genetic background which may prevent or delay the development of disease by the environmental control and genetic counseling of the high-risk family members;

(c) to enhance our understanding of disease pathogenesis better;

(d) since the clinical manifestations, treatment response, and prognosis may be heterogeneous, genetic studies may help in predicting the individual patient's clinical course and prognosis more precisely and may apply the different treatment options, providing tailored medicine.

Current evidence from familial clustering of SLE, studies on twins, and sibling recurrence risks have all established the importance of the genetic factors in the pathogenesis of the disease. Recent progress in genetics has expanded the number of the genes associated with SLE to more than 20 in number. Despite this knowledge, however, it is a challenge to fully understand the genetic pathogenesis of the disease. This is essentially because SLE features a polygenic genetic model. Moreover, it has also been proven that there are similarities and differences in SLE susceptibility loci across ethnic groups $[3,24,25]$.

The genetic loci or genes implicated in the pathogenesis of SLE can be classified into several preexisting biological pathways $[3,24,26,27]$ : (i) innate immune response including interferon signaling pathways;

(ii) adaptive immune response including B, T cells, and antigen-presenting cells;

(iii) immune complex clearance mechanisms.

Table 2 summarizes the mechanisms implicated by susceptible genes for SLE. In the genomic studies, the IFN signature first described in Caucasians have been proved in Asians, and additional work has been done to illustrate the functional implications of this IFN signature [24]. The HLA region at $6 \mathrm{p} 21.3$ has shown strongest association with SLE and is involved in both $\mathrm{B}$ cell and $\mathrm{T}$ cell signaling. HLA DR2 in some studies has been shown to be associated with early onset of disease with nephritis, and HLA DR3 has been associated with later onset and dermatitis (but less nephritis) [2]. IRF5 is the most consistent non-MHC gene in SLE and is important for transactivation of type 1 IFN and production of proinflammatory cytokines (IL6, IL12, TNF $\alpha$, IL10) [3]. Table 3 depicts the distribution of genes implicated in the causation of SLE between ethnic groups.

Significant developments have been made recently in the understanding of epigenetic (a heritable change in gene expression not due to changes in the DNA sequence) mechanisms in lupus [28]. The MECP2 gene is involved in DNA methylation. A growing body of literature opines that impaired CD4+ T cell DNA methylation, caused by environmental influences, contributes to SLE pathogenesis by altering gene expression in genetically predisposed people. This implies that preventing or correcting the altered methylation patterns may be therapeutic in SLE. However, epigenetic changes unique to SLE must be more fully characterized before such therapies can be instituted in patients with SLE.

\section{Newer Therapies}

There have been major advances in the treatment of SLE in the last decade. Newer, low dose cyclophosphamide regimes and biological agents are now being described [1]. Specific biological therapies are being developed by targeting a number of immunological abnormalities in SLE using recombinant cytokines, blocking antibodies, and soluble receptors. Gene therapy is an efficient and advantageous way of delivering immunomodulators and anti-inflammatory mediators, which include naturally occurring or genetically engineered inflammatory cytokine inhibitors (anticytokines), or potent anti-inflammatory cytokines such as TGF- $\beta[2]$. Autologous 
TABLE 2: Mechanisms implicated by susceptible genes for SLE.

\begin{tabular}{|c|c|c|}
\hline Characteristics of the gene & Genes/loci & Immunological effects \\
\hline $\begin{array}{l}\text { Genes related to innate } \\
\text { immune response }\end{array}$ & $\begin{array}{l}\text { IRF5 } \\
\text { TNFAIP3 } \\
\text { IRAK1 } \\
\text { STAT4 } \\
\text { TREX1 }\end{array}$ & $\begin{array}{l}\text { (i) IRF5 is the most consistent non-MHC gene in SLE and is important for } \\
\text { transactivation of type } 1 \text { IFN and production of proinflammatory cytokines } \\
\text { (IL6, IL12, TNF } \alpha \text {, IL10). } \\
\text { (ii) Other genes also involved in pathways of type } 1 \text { IFN production. }\end{array}$ \\
\hline $\begin{array}{l}\text { Genes related to adaptive } \\
\text { immune response } \\
\text { (T-cell signaling) }\end{array}$ & $\begin{array}{l}\text { HLA-DR } \\
\text { PTPN22 } \\
\text { STAT4 } \\
\text { PDCD1 } \\
\text { IRAK1 } \\
\text { TNFSF4 }\end{array}$ & $\begin{array}{l}\text { (i) HLA region at 6p21.3 has shown strongest association with SLE. MHC class II } \\
\text { genes influence antigen presentation by interacting with T cell receptor (TCR), and } \\
\text { susceptible HLA haplotype contributes to abnormal response to self antigens. } \\
\text { (ii) Other genes are involved in hyperactivity of T cells and failure of multiple } \\
\text { immunoregulatory circuits to down-regulate those responses. }\end{array}$ \\
\hline $\begin{array}{l}\text { Genes related to adaptive } \\
\text { immune response (B-cell } \\
\text { signaling) }\end{array}$ & $\begin{array}{l}\text { HLA-DR } \\
\text { BLK } \\
\text { BANK1 } \\
\text { LYN }\end{array}$ & $\begin{array}{l}\text { These genes are involved in hyperactivity of B cells and failure of multiple } \\
\text { immunoregulatory circuits to downregulate those responses. }\end{array}$ \\
\hline $\begin{array}{l}\text { Genes related to immune } \\
\text { complex clearing }\end{array}$ & $\begin{array}{l}\text { Complements } \\
(\text { C1q, C2, C4) } \\
\text { FCGR2A } \\
\text { FCGR3A } \\
\text { CRP } \\
\text { ITGAM }\end{array}$ & $\begin{array}{l}\text { (i) These genes are associated with dysregulated and inadequate immune complex } \\
\text { clearance in SLE. } \\
\text { (ii) ITGAM encodes integrin } \alpha \mathrm{M} \text { (complement receptor type 3) and is involved in } \\
\text { immune complex clearance, leukocyte activation, phagocytosis, and adhesion to } \\
\text { endothelia through interaction with multiple ligands, for examples, ICAM-1, C3bi, } \\
\text { fibrinogen, glycoprotein Iba. ITGAM gene plays a key role in SLE pathogenesis, } \\
\text { especially through endothelial injury. }\end{array}$ \\
\hline & & $\begin{array}{l}\text { (iii) FCGR2A and FCGR3A genes code the IgG Fc receptor IIA and IIIA. The lupus } \\
\text { predisposing polymorphisms in these genes relate to poor binding to IgG and } \\
\text { phagocytosis of immune complexes. }\end{array}$ \\
\hline $\begin{array}{l}\text { Other genes in SLE } \\
\text { pathogenesis }\end{array}$ & $\begin{array}{l}\text { MECP2 } \\
\text { ATG5 }\end{array}$ & $\begin{array}{l}\text { (i) MECP2 is involved in DNA methylation. } \\
\text { (ii) ATG5 is involved in apoptosis. }\end{array}$ \\
\hline
\end{tabular}

TABLE 3: Distribution of genes implicated in the causation of SLE between ethnic groups (adapted from [3]).

\begin{tabular}{lc}
\hline Characteristics of the genes & Genes \\
\hline & STAT4 \\
TNFAIP3 & BANK1 \\
IRAK1 & MECP2 \\
Consistent association with similar frequency between different ethnic groups & BLK \\
\hline Consistent association with different allele frequency between various ethnic groups & IRF5 \\
\hline & HLA-DRB1 \\
Allelic heterogeneity & FcGRs \\
& IRF5 \\
\hline Genetic heterogeneity & PTPN22 \\
ITGAM & PXK \\
LYN
\end{tabular}

stem-cell transplantation has been viewed with some caution in the management of severe lupus on account of the substantial treatment-related morbidity and mortality [1].

Before modern treatment was available, the 2-year survival rate in severe lupus nephritis was $50 \%$ or less. The advent of treatment with steroids, cyclophosphamide, and azathioprine greatly improved the outcome, and typical 10-year patient survival increased to $90 \%$. The mortality has since then not improved in any very substantial way. The side effects from both steroids and cyclophosphamide are also 
substantial. There is therefore a great need to find more effective treatments with, if possible, less side effects. Such developments are ongoing [29].

4.1. Mycophenolate Mofetil (MMF). MMF is currently being used as a major part of both induction and maintenance treatment both in children and adults. The drug compares well to cyclophosphamide for induction, in terms of efficacy as well as relatively fewer side effects. However, data is scanty in children. Still MMF is regarded by some authors as part of standard treatment for children with severe lupus [29].

4.2. Rituximab. Rituximab is a human-murine chimeric monoclonal antibody against CD20 on B cells and their precursors but not plasma cells, which do not possess this antigen. Rituximab has effects on the interaction between regulatory $\mathrm{T}$ cells and B cells that extend beyond simple B-cell depletion [1]. Substantial and prolonged remissions in lupus patients, who were previously unresponsive to conventional and novel immunosuppressive agents, such as MMF $[1,29]$ have been described. Combinations with rituximab with intravenous cyclophosphamide and methylprednisolone have been used. However, the first randomized controlled trial assessing the efficacy of rituximab, EXPLORER, did not find any difference between rituximab and placebo [30]. Further randomized controlled trials are needed to address the efficacy of rituximab.

4.3. Biological Agents. Scanty data regarding some recent drugs affecting $B$ cells in lupus are available $[1,29]$. These drugs are still in the experimental stage, and further studies are required.

These include the following.

(a) Ocrelizumab: ocrelizumab is a humanized antibody that targets CD20-positive B cells. It is a "nextgeneration rituximab" where the potential problem of development of HACAs (Human Anti-chimeric Antibodies) is ameliorated.

(b) Belimumab: belimumab is a fully humanized monoclonal antibody that binds to soluble BLyS (B-lymphocyte stimulator) and acts as a specific inhibitor of its biological activity. BLyS, also known as BAFF (B-cell activating factor), is an immunomodulatory cytokine that promotes B-cell survival, B-cell differentiation, and immunoglobulin class switching.

(c) Epratuzumab: epratuzumab is a monoclonal antibody against $\mathrm{CD} 22$, another B-cell-specific surface antigen.

(d) Atacicept: atacicept is a receptor analogue that binds both BAFF and APRIL (A Proliferation-Inducing Ligand) two related members of the TNF (Tumour Necrosis Factor) superfamily. This drug has been shown to have a dramatic effect on plasma cells.

(e) Tocilizumab: tocilizumab is a humanized monoclonal antibody against the IL-6 receptor. (f) Infliximab: it is a monoclonal antibody against tumour necrosis factor alpha (TNF $\alpha)$.

(g) Abatacept: abatacept is a fusion protein composed of an immunoglobulin fused to the extracellular domain of cytotoxic T-lymphocyte antigen (CTLA).

Drug therapy of lupus is currently a very rapidly growing area with many recently completed or ongoing studies in adults. Unfortunately, data is scanty for pediatric population. Extrapolating from adult studies, MMF has gained an important role both in induction and maintenance treatment of children with lupus. Some authors have opined that either a cyclophosphamide infusion or MMF can be used as induction therapy in children with lupus nephritis class III or higher [29]. Both azathioprine and MMF can be used as a maintenance treatment [29]. Rituximab should be used in selected cases with treatment-resistant lupus nephritis [29]. Belimumab is the most promising new drug that is likely to soon be available for the treatment of lupus. There are, however, no studies with belimumab in children or adults with lupus nephritis. A number of other drugs are under evaluation.

4.4. Intravenous Immunoglobulin. Intravenous immunoglobulins (IVIg) are increasingly being used in the treatment of resistant lupus [31], although there are no large randomized trials. These drugs have a role in patients who have simultaneous infection and active lupus in whom immunosuppression is risky. They have also been used in the treatment of a wide range of clinical manifestations in lupus patients. The mechanisms of action of IVIg in autoimmune diseases are diverse and include all arms of the immune system. Anti-idiotypic antibodies within IVIg directed towards pathogenic idiotypes that are found over autoantibodies are implicated in these mechanisms of action of IVIg [32].

4.5. TGF $\beta 1$, a Potent Anti-Inflammatory Cytokine. TGF- $\beta 1$ is released by T-lymphocytes (some called regulatory or TH3 cells), macrophages, and many other cell types in various tissues. It exerts multiple immune-inhibitory effects on Blymphocytes, $\mathrm{CD}_{4}^{+}$T-lymphocytes (TH1 or $\mathrm{TH} 2$ ), $\mathrm{CD}^{+}$ cytotoxic T-lymphocytes (CTLs), NK cells, lymphokineactivated killer (LAK) cells, and macrophages. However, gene therapy approaches of delivery using intramuscular injection of naked plasmid DNA encoding latent TGF$\beta 1$ have produced variable, inconsistent, and contradictory results, which demonstrate the risks inherent in using cytokines as therapeutic molecules [2]. Most cytokines have complex pleiotropic actions and may have stimulatory or inhibitory effects depending on their concentration, target tissue, or cell, as well as interacting cytokines in the extracellular milieu. Thus, cytokines that are generally thought of as anti-inflammatory, such as TGF- $\beta 1$, sometimes have inflammatory effects. An alternative approach to using inhibitory cytokines involves blocking costimulation with molecules such as cytotoxic T-lymphocyte antigen 4-Ig (CTLA-4/Ig) recombinant protein that mask a T-cell stimulatory molecule or its ligand. 
TABLE 4: Summary of newer therapies for SLE.

\begin{tabular}{lc}
\hline & Rituximab \\
Ocrelizumab & Belimumab \\
Epratuzumab & Atacicept \\
Biological agents & Tocilizumab \\
Infliximab & Abatacept \\
\hline Anticytokine therapies & Anti-TNF $\alpha$ \\
Anti-interleukin 10 & Anti-interleukin 6 receptor \\
Anti-interleukin 1 receptor & Anti- IFN $\alpha$ \\
\hline Immunoadsorption \\
Anti-C5a \\
Peptide therapies \\
T cell vaccination \\
Other techniques
\end{tabular}

4.6. Gene Therapy with Cytokine Inhibitors. Compared with cytokines, cytokine inhibitors (such as antibodies or soluble receptors) are nontoxic and has a loner half life in body fluids. Transfer of cDNA encoding these molecules protects against several autoimmune diseases. Treatment with the IFN- $\gamma \mathrm{R} / \mathrm{IgG} 1$ plasmid by intramuscular injections have been shown in animal models, to protect from early death, reduced autoantibody titres, renal disease, and histological markers of lupus-like disease [2]. Such gene therapy approaches are a promising tool. The gene therapy of lupus is still in its infancy, and there are only a limited number of reported studies in the literature. Viral and nonviral vectors have been used to protect against organ-specific and systemic autoimmune diseases in several models. Table 4 summarizes the newer therapies for SLE.

\section{Conclusions}

(1) Recent advances in the delineation of the key molecular pathways implicated in the pathogenesis of SLE and understanding of the function of the lupus disease genes will enhance the development of novel therapeutic targets and biomarkers for individualized clinical management of lupus patients.

(2) Attempts to identify ethnic-specific genetic factors or disease-causing variants are necessary for genetic dissection of SLE and delineate genotype-phenotype correlations.

(3) Drug therapy of lupus is currently a very rapidly growing area with many recently completed or ongoing studies in adults. Unfortunately, data is scanty for pediatric population, and more studies are required.
(4) Gene therapy and biological agents are promising tools for the management of SLE in the future.

\section{Authors' Contribution}

Sriram Krishnamurthy and Subramanian Mahadevan reviewed the literature. Sriram Krishnamurthy drafted the paper. S. Mahadevan critically revised the paper. Both authors approved the final version of the paper.

\section{Conflict of Interests}

The authors declared that there is no conflict of interests.

\section{References}

[1] D. P. D'Cruz, M. A. Khamashta, and G. R. Hughes, "Systemic lupus erythematosus," The Lancet, vol. 369, no. 9561, pp. 587596, 2007.

[2] R. A. Mageed and G. J. Prud'homme, "Immunopathology and the gene therapy of lupus," Gene Therapy, vol. 10, no. 10, pp. 861-874, 2003.

[3] H. S. Lee and S. C. Bae, "What can we learn from genetic studies of systemic lupus erythematosus? Implications of genetic heterogeneity among populations in SLE," Lupus, vol. 19, no. 12, pp. 1452-1459, 2010.

[4] K. L. Hardgrave, B. R. Neas, R. H. Scofield, and J. B. Harley, "Antibodies to vesicular stomatitis virus proteins in patients with systemic lupus erythematosus and in normal subjects," Arthritis and Rheumatism, vol. 36, no. 7, pp. 962-970, 1993.

[5] D. Deapen, A. Escalante, L. Weinrib et al., "A revised estimate of twin concordance in systemic lupus erythematosus," Arthritis and Rheumatism, vol. 35, no. 3, pp. 311-318, 1992.

[6] M. L. Snaith and D. A. Isenberg, "Systemic lupus erythematosus," in Oxford Textbook of Medicine, D. J. Weatherall, J. G. G. Ledingham, and D. A. Warrell, Eds., pp. 3017-3026, Oxford University Press, New York, NY, USA, 3rd edition, 1996.

[7] M. Goto, K. Tanimoto, and Y. Horiuchi, "Natural cell mediated cytotoxicity in systemic lupus erythematosus. Suppression by antilymphocyte antibody," Arthritis and Rheumatism, vol. 23, no. 11, pp. 1274-1281, 1980.

[8] M. Linker-Israeli, F. P. Quismorio Jr., and D. A. Horwitz, "CD8+ lymphocytes from patients with systemic lupus erythematosus sustain, rather than suppress, spontaneous polyclonal IgG production and synergize with CD4+ cells to support autoantibody synthesis," Arthritis and Rheumatism, vol. 33, no. 8, pp. 1216-1225, 1990.

[9] K. Ohtsuka, J. D. Gray, M. M. Stimmler, B. Toro, and D. A. Horwitz, "Decreased production of TGF- $\beta$ by lymphocytes from patients with systemic lupus erythematosus," Journal of Immunology, vol. 160, no. 5, pp. 2539-2545, 1998.

[10] J. D. Gray, M. Hirokawa, K. Ohtsuka, and D. A. Horwitz, “Generation of an inhibitory circuit involving CD8+ T cells, IL-2, and NK cell-derived TGF- $\beta$ : contrasting effects of anti-CD2 and anti-CD3," Journal of Immunology, vol. 160, no. 5, pp. 2248-2254, 1998.

[11] L. J. Mason and D. A. Isenberg, "Immunopathogenesis of SLE," Bailliere's Clinical Rheumatology, vol. 12, no. 3, pp. 385403, 1998.

[12] A. E. Traynor, J. Schroeder, R. M. Rosa et al., "Treatment of severe systemic lupus erythematosus with high-dose chemotherapy haemopoietic stem-cell transplantation: a phase I study," The Lancet, vol. 356, no. 9231, pp. 701-707, 2000. 
[13] M. Pavlovic, A. Kats, M. Cavallo, R. Chen, J. X. Hartmann, and Y. Shoenfeld, "Pathogenic and epiphenomenal anti-DNA antibodies in SLE," Autoimmune Diseases, vol. 2010, Article ID 462841, pp. 1-19, 2010.

[14] S. Patra, S. Krishnamurthy, A. Seth, S. Beri, and S. Aneja, "Bilateral optic neuritis in pediatric systemic lupus erythematosus with antiphospholipid antibody syndrome," Indian Journal of Pediatrics, vol. 78, no. 2, pp. 234-236, 2011.

[15] G. J. Prud'Homme, D. H. Kono, and A. N. Theofilopoulos, "Quantitative polymerase chain reaction analysis reveals marked overexpression of interleukin- $1 \beta$ interleukin-10 and interferon- $\gamma$ mRNA in the lymph nodes of lupus-prone mice," Molecular Immunology, vol. 32, no. 7, pp. 495-503, 1995.

[16] T. B. Niewold, J. Hua, T. J. A. Lehman, J. B. Harley, and M. K. Crow, "High serum IFN- $\alpha$ activity is a heritable risk factor for systemic lupus erythematosus," Genes and Immunity, vol. 8, no. 6, pp. 492-502, 2007.

[17] L. Rönnblom, G. V. Alm, and M. L. Eloranta, “Type I interferon and lupus," Current Opinion in Rheumatology, vol. 21, no. 5, pp. 471-477, 2009.

[18] W. B. Graninger, W. Hassfeld, B. B. Pesau, K. P. Machold, C. C. Zielinski, and J. S. Smolen, "Induction of systemic lupus erythematosus by interferon- $\gamma$ in a patient with rheumatoid arthritis," Journal of Rheumatology, vol. 18, no. 10, pp. 1621$1622,1991$.

[19] M. J. Walport, "Complement and systemic lupus erythematosus," Arthritis Research, vol. 4, supplement 3, pp. S279-S293, 2002.

[20] X. Wu, N. Jiang, C. Deppong et al., "A role for the Cr2 gene in modifying autoantibody production in systemic lupus erythematosus," Journal of Immunology, vol. 169, no. 3, pp. 15871592, 2002.

[21] J. E. Salmon, S. Millard, L. A. Schachter et al., "Fc $\gamma$ RIIA alleles are heritable risk factors for lupus nephritis in African Americans," Journal of Clinical Investigation, vol. 97, no. 5, pp. 1348-1354, 1996.

[22] P. Kraft and D. J. Hunter, "Genetic risk prediction-are we there yet?" The New England Journal of Medicine, vol. 360, no. 17, pp. 1701-1703, 2009.

[23] R. M. Plenge, "Recent progress in rheumatoid arthritis genetics: one step towards improved patient care," Current Opinion in Rheumatology, vol. 21, no. 3, pp. 262-271, 2009.

[24] Y. J. Yuan, X. B. Luo, and N. Shen, "Current advances in lupus genetic and genomic studies in Asia," Lupus, vol. 19, no. 12, pp. 1374-1383, 2010.

[25] L. S. Teh, D. G. Doherty, and R. D. Williams, "HLA-DRB genes and antiribosomal $\mathrm{P}$ antibodies in systemic lupus erythematosus," British Journal of Rheumatology, vol. 33, no. 12, pp. 1125-1126, 1994.

[26] K. L. Moser, J. A. Kelly, C. J. Lessard, and J. B. Harley, "Recent insights into the genetic basis of systemic lupus erythematosus," Genes and Immunity, vol. 10, no. 5, pp. 373-379, 2009.

[27] L. Morel, "Genetics of human lupus nephritis," Seminars in Nephrology, vol. 27, no. 1, pp. 2-11, 2007.

[28] D. R. Patel and B. C. Richardson, "Epigenetic mechanisms in lupus," Current Opinion in Rheumatology, vol. 22, no. 5, pp. 478-482, 2010.

[29] K. Tullus, "New developments in the treatment of systemic lupuserythematosus," Pediatric Nephrology. In press.

[30] J. T. Merrill, C. M. Neuwelt, D. J. Wallace et al., "Efficacy and safety of rituximab in moderately-to-severely active systemic lupus erythematosus: the randomized, double-blind, phase II/III systemic lupus erythematosus evaluation of rituximab trial," Arthritis and Rheumatism, vol. 62, no. 1, pp. 222-233, 2010.

[31] G. Chetan, S. Mahadevan, K. Sulanthung, and P. Narayanan, "Intravenous immunoglobulin therapy of lupus pneumonitis," Indian Journal of Pediatrics, vol. 74, no. 11, pp. 1032-1033, 2007.

[32] Y. Sherer, S. Kuechler, J. J. Scali et al., "Low dose intravenous immunoglobulin in systemic lupus erythematosus: analysis of 62 cases," Israel Medical Association Journal, vol. 10, no. 1, pp. 55-57, 2008. 


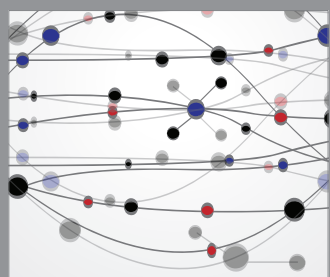

The Scientific World Journal
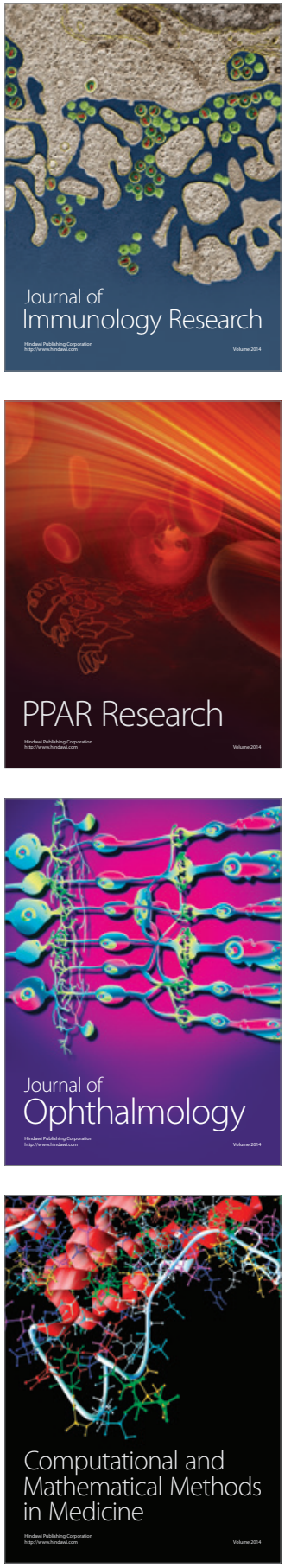

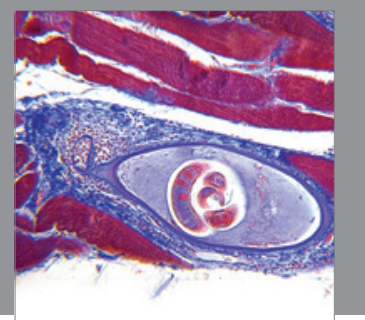

Gastroenterology

Research and Practice
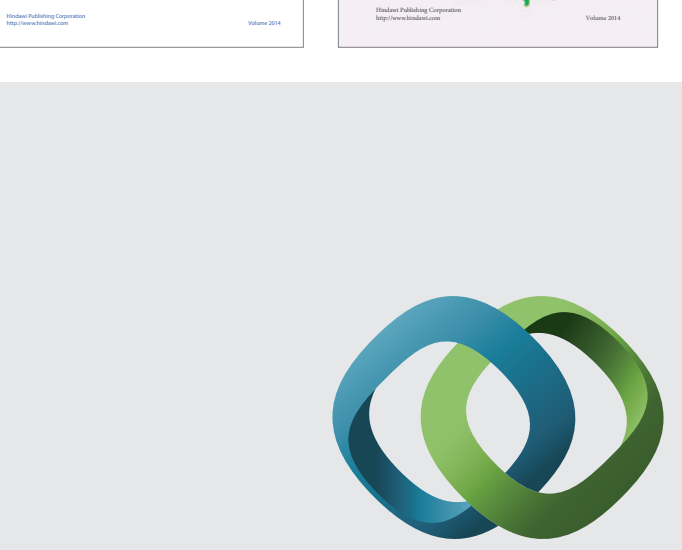

\section{Hindawi}

Submit your manuscripts at

http://www.hindawi.com
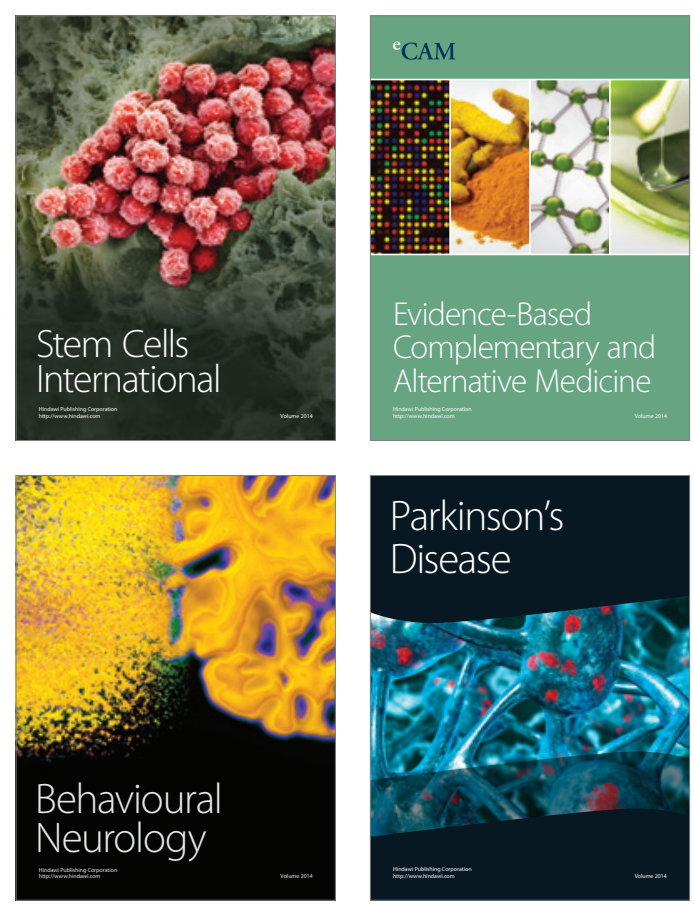



Journal of
Diabetes Research

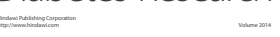

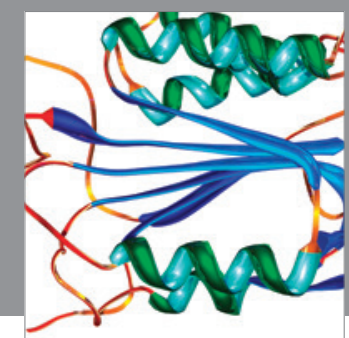

Disease Markers
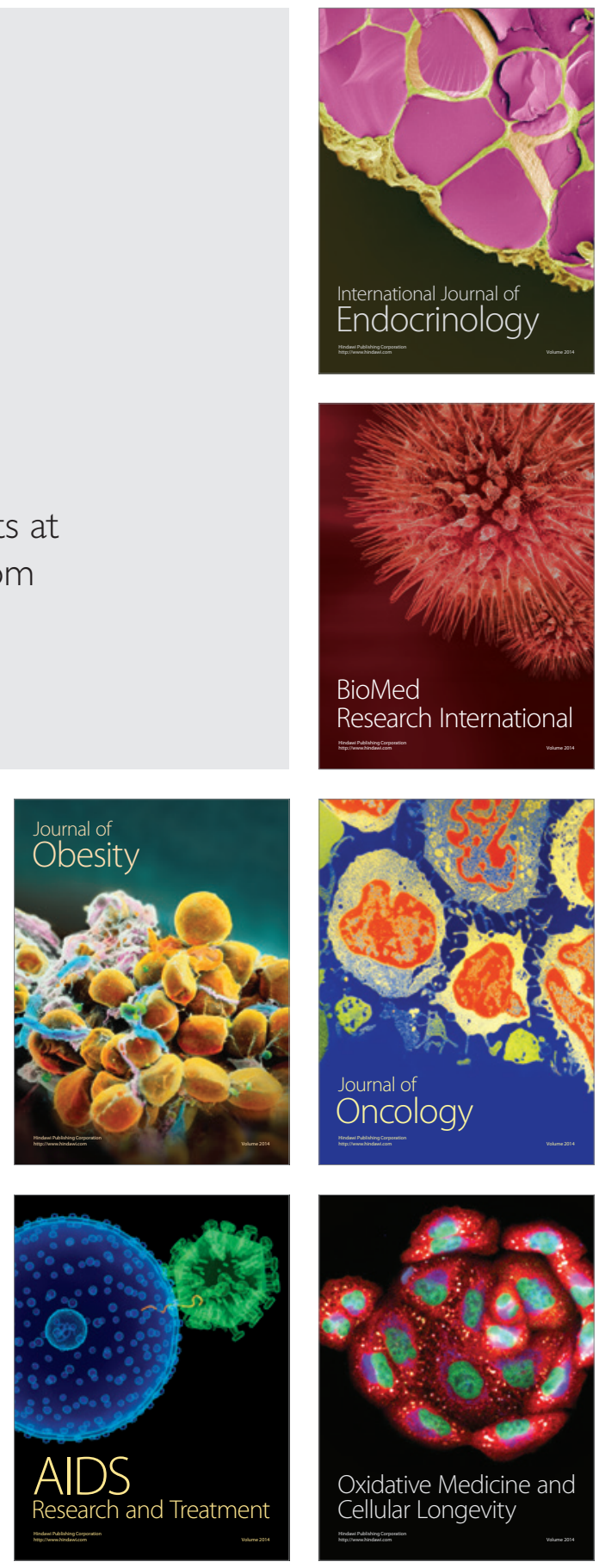